\title{
THE ANAESTHETIC MANAGEMENT OF POSTERIOR FOSSA EXPLORATIONS IN INFANTS*
}

\author{
David Allan, M.B., CH.B., Hyo Sook Kim, M.D., AND John M. Cox, M.B., B.s.†
}

Providing anaesthesia with minimum risk to the patient and optimum conditions for a neurosurgeon is challenging under any circumstances. When the patient is an infant from birth to two years of age, however, and the procedure is exploration of the posterior fossa in the sitting position, the challenge, along with the difficulties, increases exponentially.

Many surgeons prefer with good reason to operate with the patient upright and slightly above eye level, regardless of age or size. ${ }^{1}$ There are advantages for the anaesthesiologist too. Yet the upright position, during general anaesthesia, creates exigencies as well. These include: maintaining the airway, controlling temperature, supporting cardiovascular tone, ${ }^{2}$ estimating blood loss, preserving biochemical balances by mechanical ventilation, and preventing air embolus. Demanding enough in adults, these challenges become maximized in infants. For example, a percentage of blood loss which can be tolerated by an adult may be critical in a young child. In a seated patient, however, there is no satisfactory way to collect blood to measure what has been lost (or to separate blood from the result of saline washings). In an adult, a 10 per cent blood loss may range from $350 \mathrm{ml}$ to $700 \mathrm{ml}$ depending on body size, but in an infant 10 per cent of volume is $30 \mathrm{ml}$; loss of this amount can be overwhelming. If 20 per cent redistribution of blood volume occurs because of hydrostatic factors, this also poses considerable risk to the very young.

Ventilation, too, has special hazards. ${ }^{3}$ Although babies have comparatively high metabolic rates, lung reserve capacity is at lower levels than in adults. An infant must process about twice as much air relatively, to provide equal gas transfer. Tracheas and bronchi are about one quarter adult size (anatomical relationships and calibre of the larynx make endotracheal intubation a delicate, precise procedure). In addition, physiological deadspace is relatively larger. If respiratory volume per minute is stepped up by ventilation, this will increase gas flow through the infant trachea, but resistance will be far greater than for the same added rate of flow in an adult.

Babies and young children also have labile, often precipitate, temperature reactions. Untoward heat $\operatorname{loss}^{4}$ or sudden extreme hyperthermia may occur. ${ }^{5}$ These and other concerns, entirely apart from emergencies such as air embolus, ${ }^{0}$ demand alertness, continuous monitoring, and meticulous management. We shall

This work was supported in part by PHs grant no. FR-05475-05.

†Dr. Allan is Head, Division of Anesthesiology, Children's Memorial Hospital, Chicago, and Associate Professor of Anesthesia at Northwestern University Medical School. Dr. Kim is a Fellow in Anesthesia at Children's Memorial Hospital. Dr. Cox is Assistant Head, Division of Anesthesiology, Children's Memorial Hospital, and Assistant Professor of Anesthesia, Northwestern University Medical School.

Canad. Anaesth. Soc. J., vol. 17, no. 3, May 1970 
describe a method developed at Children's Memorial Hospital for the anaesthetic management of these patients.

\section{METHOD}

Eighteen infants, ranging from 15 days to two years of age, were studied during the past two years while undergoing posterior fossa exploration in the upright position. Body weight varied from 3.5 to $12.6 \mathrm{~kg}$. We used atropine sulphate only, for presurgical medication of infants under $12 \mathrm{~kg}$ in weight, without regard to the proposed operation. In this series, each patient received 0.1 to $0.2 \mathrm{mg}$ atropine intramuscularly, 30 to 60 minutes before induction of anaesthesia.

Anaesthesia was induced with nitrous oxide and oxygen (50:50 ratio), ${ }^{7}$ followed by the addition of halothane from a Fluotec vaporizer to 2.5 per cent. With appearance of surgical anaesthesia, the halothane percentage was reduced to 1.5 or 1 per cent.

A non-rebreathing, valveless technique which reduces resistance to expiration to a minimum is preferred. This is a modification of the Ayre's T-piece, connected to the patient by mask or endotracheal tube. Gas is conveyed to the patient through one end of the T-piece and empties into an open-ended reservoir bag. The gas flow is 2.5 to 3 times the patient's minute volume. Humidity and warmth are applied to the gases by interposing an ultrasonic nebulizer between machine and patient. Since humidity and hypothermia became critical factors in long operations, we employ ultrasonic nebulizers for the majority of our paediatric patients. In patients weighing $12 \mathrm{~kg}$ or more, we prefer the non re-breathing technique with one-way valves, to avoid an impractically high minute volume How of anaesthetic gases. ${ }^{8}$

After 3 to 5 minutes, $3 \mathrm{mg} / \mathrm{kg}$ of succinylcholine was injected intramuscularly or intravenously, the lungs were ventilated with 100 per cent oxygen for 2 to 3 minutes, and tracheal intubation was performed with a well-lubricated anode, or armored tube guided by a flexible stylet. Respiration was maintained by an Engström respirator with controlled positive pressure throughout the operation. Peak pressure on expiration varied from 20 to $30 \mathrm{~cm} \mathrm{H}_{2} \mathrm{O}$. With considerably more resilient cardiovascular systems than adults and no pathology due to aging, infants and children tolerate positive pressure ventilation well. The majority of our anaesthetics are associated with surgical procedures continuing for four hours or longer. This makes mechanical ventilation preferable to manual control of respiration, in our view. An anaesthesia circuit designed for the Engström respirator has permitted us to quantitate the anaesthesia mixture and the ventilatory volumes necessary for the management of infants. ${ }^{9-11}$ This semi-automated method reduces anaesthesiologist fatigue.

As a guide to adequacy of ventilation, respiratory rates and minute volumes were calculated by using the Herzog ventilation nomogram for the Engström respirator, and were verified as needed by blood gas analysis. Verification can be done rapidly in a laboratory adjacent to the operating suite, and technicians were always on duty. 
In the majority of the patients, the average halothane concentration maintained varied from 0.5 to 1 per cent with nitrous oxide and oxygen in a 50:50 ratio.

During the operation cardiac and ventilatory adequacy were monitored with the electrocardiograph and oesophageal stethoscope. Temperature was monitored continuously with a rectal or oesophageal thermistor. Blood pressure was measured by an oscillometer with appropriate selection of cuffs.

Body temperature was maintained as close to normal as possible. Several covered mattresses circulating 20 per cent alcohol in water were wrapped around the babies, since the small size and the sitting position made the use of large mattresses awkward. Servomechanisms, connected with a cooling/heating pump located outside the operating room, automatically controlled mattress temperatures between $60^{\circ}$ and $105^{\circ} \mathrm{F}$. Because contact of the thermal blankets with a seated patient is difficult to achieve, radiant heat temperature control systems are now being developed.

Blood for transfusion was also warmed. Heat loss from respiratory tract, blood vessels, cavity and body surfaces appeared to be minimized.

Following induction of anaesthesia an 18-gauge cannula was placed intravenously in all the patients. In about half the infants an indwelling catheter could be directed into the right atrium through the antecubital or femoral vein. This accomplished two things: it gave an opportunity to assess central venous pressure and it provided a means to aspirate air. ${ }^{12}$

The patients' abdomen and legs from toes to the top of the thighs were wrapped in tensor bandages to support cardiovascular tonus. In addition, the legs were kept slightly elevated throughout the surgical procedure to prevent venous pooling in the lower extremities.

When respiration was controlled and airway obstruction ruled out, and when pulse and blood pressure had settled into normal ranges as indicated by the monitors, the patients were slowly and gently placed in a sitting position. This was accomplished by flexing the regular operating table while keeping close watch on blood pressure as influenced by the changing position. The patients eventually sat on interlocked footstools which boosted them to the desired height for the head holder. Once a patient reached a sitting position, the headpiece of the table was detached, and the head was then fixed with care, anteriorly. This was done meticulously to avoid possibility of slipping and to prevent pressure on the eyeballs and other soft parts of the face. To protect the eyes, petroleum jelly was first applied over the lids, then a felt pad was fitted over each, followed by an aluminum guard, taped securely. This prevents injury to nerves and corneae.

Blood volume of the study patients was estimated at $80 \mathrm{ml} / \mathrm{kg}$ of body weight. Blood, warmed to body temperature by passage through a haemocoil in a water bath, was transfused to maintain 10 per cent of calculated blood volume in positive balance. Blood loss was estimated.

On completion of surgery, the patients were allowed to breathe spontaneously. The change from upright to supine position was made slowly-over a period of 20 to 30 minutes, with due attention to the blood pressure oscillograph to prevent abrupt redistribution of blood volume. When the patients were finally lying flat 
and their vital signs were stabilized, endotracheal tubes were removed after thorough suctioning of the pharynx. This was done while the babies were still asleep, to prevent bucking or straining, which would affect blood pressure adversely. Then 100 per cent oxygen was administered by mask until they regained consciousness. All were awake and responding before they left the operating room.

\section{REsults}

Pathological findings are indicated in Table I. In the 18 study patients there was no mortality or morbidity due to anaesthesia. Two patients expired, one from tuberculous meningitis on the twelfth postoperative day and the other from severe ventriculitis five months following surgery. One other complication developed after the operation: a recurrent abscess of the wound.

TABLE I

\begin{tabular}{lc}
\hline \hline Condition & Incidence \\
\hline Encephalocele & 3 \\
Tumour & 2 \\
Haemorrhage & 2 \\
Arachnoid cyst & 4 \\
Arnold-Chiari & \\
malformation & 5 \\
Abscess & 2 \\
\hline
\end{tabular}

The posterior fossa explorations lasted from two hours, 30 minutes, to eight hours; the average time was four hours. There was no significant temperature change.

Blood loss, impossible to assess accurately, was visually estimated to be from $60 \mathrm{ml}$ to $500 \mathrm{ml}$, with an average loss calculated at $200 \mathrm{ml}$. Under the circumstances of this type of surgery, experience becomes the criterion for such estimates, unsatisfactory though that may be, and because of the risks inherent in infant blood loss, replacement is made without hesitation. Transfusion of 35 to $50 \mathrm{ml}$ in a young baby, for example, is equivalent to 1 to 2 units for the adult, and we feel it entirely justified.

There were no significant electrocardiographic changes nor alterations in vital signs, except in one patient who developed two episodes of hypotension associated with bradycardia. This happened during surgical manipulation of the intracranial lesion. Because of the precautions taken, the upright position was not associated with hypotension. There was no evidence of air embolism such as ECG changes, heart murmur, or severe hypotension. ${ }^{13}$

Controlled positive pressure ventilation was at normal or slightly hyperventilated levels. While hyperventilation may decrease the concentration of gases required for anaesthesia, the surgeon may want to use the quality of respiration during neurological procedures as a guide to anatomical dissection. Spontaneous respiration, in such instances, ensues immediately only if the $\mathrm{Pa}_{\mathrm{CO}_{2}}$ is near normal. Consequently, we prefer to keep ventilation constantly within normal range (arterial $\mathrm{pH} 7.34-7.38 ; \mathrm{P}_{\mathrm{CO}_{2}} 36-40 \mathrm{~mm} \mathrm{Hg}$ ) with adequate oxygenation. When 
the respirator is shut off, the patient will breathe spontaneously in about 30 seconds, and the quality of this respiration becomes the surgeon's guide. However, when cerebral oedema is thought to exist, hyperventilation is used throughout the procedure. The combination of no-kink tube, the respiratory circuit with low resistance, and sufficient anaesthesia to avoid straining gives satisfactory results.

Dehydrating agents (hypertonic solutions) were not needed to reduce intracranial tension. In the postoperative period the patients were monitored carefully for any signs of increased cerebrospinal fluid pressure.

\section{Discussion}

In adults, mortality in posterior fossa craniotomy is relatively high, reported around 20 per cent. Morbidity in adults is also frequently cited. ${ }^{14}$ Perhaps higher mortality and morbidity findings than ours might be due in part to insufficient care in positioning the patient and to lack of additional precautions against vasomotor instability, such as tensor wrappings. Other factors may include increased sensitivity to depressant drugs, hypovolaemia due to blood loss, and the fact that the surgical area itself abounds with vital centres.

Air embolism is the most common cause of complications and death following exploration of the posterior fossa in the upright patient. This may happen because air is aspirated after exposed dural sinuses and vessels are opened in the presence of negative venous pressure. Hunter ${ }^{14}$ suggested that even effective positive pressure ventilation without a negative phase does not preclude this possibility. With controlled positive pressure ventilation, Michenfelder ${ }^{12}$ reported air embolism in 11 patients out of 418 ( 2.6 per cent) over a four-year period. This compares to 15 per cent in 34 patients breathing spontaneously, reported by Marshall. ${ }^{13}$ The likelihood of air embolism may be lessened by frequent irrigation of the wound with saline, application of bone wax by the surgeon, ${ }^{12}$ and intermittent pressure on the jugular veins of the neck. ${ }^{14}$ Constant watch on arterial blood pressure, heart beat, and ECG, and frequent measurement of central venous pressure serve admirably to detect any change in cardiovascular status and to indicate the adequacy of tissue perfusion. Additionally, continuous monitoring assists diagnosis and treatment should air embolism intervene.

When anaesthesia extends over hours, the sympathetic nervous system becomes depressed; homeostatic mechanisms cease to be effective. Yet hypotension related to postural change can be avoided, and prompt transfusion will prevent hypovolaemia. Hypotension caused by positive pressure ventilation rarely develops, in our experience.

Vagal arrhythmias commonly occur in children during induction, especially at the time of endotracheal intubation. This is most liable to happen when succinylcholine injected intravenously or intramuscularly accompanies the use of halothane. We, and others, have found that a relatively high dosage of atropine is effective to prevent or obliterate such disturbances.

Cardiac arrhythmias occur in posterior fossa operations. J. D. Whitby ${ }^{15}$ reported in 1963 that the ECC detected these irregularities in 51 per cent of adult patients. 
Briggs and Beecher ${ }^{16}$ stated in 1956 that 13 instances of arrhythmia were found among 200 cardiac arrests, or 6.5 per cent. Anaesthetic agents, including halothane, have been implicated in these disturbances. Alfonso Schettini, ${ }^{17}$ reporting in 1969, did not find any significant alteration in ECG pattern when concentrations less than 1.0 per cent of halothane were employed in neurosurgery. When concentrations rose above 1.4 per cent, however, 18 of 40 patients ( 45 per cent) had electrocardiographic changes. None of our patients had significant ECC alterations. During surgery here, halothane concentration was kept below 1 per cent. Ventilation at normal or slightly higher levels prevented $\mathrm{CO}_{2 .}$ build-up, which is a consequence of hypoventilation, and there was sufficient oxygenation. Support of cardiovascular status ruled out other reasons for ECG change.

Because babies have a relatively large body surface area, they are virtually poikilothermic. Such response to the environment may also precipitate reactions if babies encounter temperature fluctuations, such as unwarmed gases and transfused blood and fluctuations in skin temperature.

\section{SUMMARY}

Eighteen infants were studied during surgical exploration of the posterior fossa in the sitting position. Our patient management is developed to avoid or minimize hypotension, vagal and cardiac arrhythmias, ventilation difficulties, air embolism, and abnormally low temperature.

\section{RÉSUMÉ}

Nous avons étudié 18 enfants qui ont subi une exploration chirurgicale de la fosse postérieure en position assise. Nos soins pour le malade visent à éviter ou à diminuer le plus possible l'hypotension, la stimulation vagale et les arythmies cardiaques, les problèmes de ventilation, l'embolie gazeuse et une température trop basse.

\section{REFERENCES}

1. Hewer, A. J. Method of Increasing the Safety of Neuroanaesthesia in the Sitting Position. Anaesthesia. 17: 476 (1962).

2. Howland, W. S. \& PAPPER, E. M. Circulatory Changes during Anesthesia for Neurosurgical Operations. Anesthesiology. 20:65 (1959).

3. McDonald, I. H. Infant Physiology and Anaesthesia. Brit. J. Anaesth, 32: 22 (1960).

4. Farman, J. V. Heat Loss in Infants Undergoing Surgery in Air Conditioned Theaters. Brit. J. Anaesth. 24: 543 (1962).

5. Relton, J. W.; Creighton, R. E.; Johnston, A. E.; Pelton, D. A.; \& Conn, A. W. Hyperpyrexia in Association with General Anaesthesia in Children. Canad. Anaesth. Soc. J. 13: 419 (1966).

6. Tisovec, L. \& Hamilton, W. K. Newer Considerations in Air Embolism during Operation. J.A.M.A. $201: 376$ (1967).

7. Munson, E. \& Merruck, H. C. Effect of Nitrous Oxide on Venous Air Embolism. Anesthesiology. 27: 783 (1966).

8. Marrubini, M. L. General Anaesthesia for Intra-Cranial Surgery. Brit. J. Anaesth. 27: $268(1965)$.

9. Gorwh, T. \& Hallem, B. The Concentration of Halothane by the Combined Use of Fluotec Vaporizer and Engström Respirator. Acta Anaesth. Scandinav. 8: 97 (1964).

10. Foster, P. A. \& Martinez, L. The Performance of the Engström Ventilator. Anaesthesiology. 27: 504 ( 1966). 
11. Seleny, F, L. Die Narkose in der Herz- und Gefass- Chirurgie bei Kindern: Ein modifziertes Engström-Gerät. Anaesth. und Wiederbel. 20: 23 (1967).

12. Michenfelden, J. D.; Terry, H. R., Jr.; Daw, E. F.; \& Miller, R. H. Air Embolism during Neurosurgery: A New Method of Treatment. Anesth. Analg. 45: 390 (1966).

13. Marshall, B. M. Air Embolus in Neurosurgical Anesthesia: Its Diagnosis and Treatment. Canad. Anaesth. Soc. J, 12: 255 ( 1965 ).

14. Hunter, A, R, \& Inglis, J. M. Discussion on the Value of Controlled Respiration in Neurosurgery. Proc. Roy. Soc. Med. 53: 365 (1960).

15. Whitby, J. D. Electrocardiography during Posterior Fossa Operations. Brit. J. Anaesth. 35: 624 (1963).

16. Bricgs, B. D.; Sheldon, D. B.; \& Beecher, H. K. Cardiac Arrest: Study of a 30-Year Period of Operating Room Deaths at Massachusetts General Hospital, 1925-1954. J.A.M.A. 160: 1439 ( 1956$)$.

17. Schetrini, A.; Cook, A. W.; \& Owre, E. S. Hyperventilation in Craniotomy for Brain Tumor. Anesthesiology. 28: 363 (1967). 